\title{
VIOLÊNCIA E RESISTÊNCIA NO DISCURSO DE SARAMAGO: ANOTAÇÕES SEMIÓTICAS
}

\section{RESUMO}

José Leite Jr. ${ }^{1}$

Este estudo centra-se na questão da violência na obra literária de José Saramago, escritor Português, até agora único caso a ganhar o Prêmio Nobel de Literatura em português. De todos os títulos deste autor, foram separados para a presente análise os seguintes exemplos, porque são representativas de momentos significativos de sua maturidade literária: Levantado do Chão (1980), este apenas para a exemplificação metodológica introdutória, O ano de 1993 (1975), Memorial do Convento (1982) e Ensaio sobre a Cegueira (1995). A abordagem é baseada em categorias analíticas de Semiótica fundada por Algirdas Julien Greimas, segundo a qual qualquer texto tem três níveis de abstração na produção de significado: o nível fundamental, o nível de narrativa e de nível discursivo. No nível discursivo, parece que o texto de Saramago reitera temas e figuras que confirmam o apoio ideológico deste escritor aos interesses das classes oprimidas em sua missão histórica da emancipação. No processo, as mulheres desempenham papel de liderança no texto de Saramago. No nível narrativo, o efeito discursivo é realizado pela representação de um sujeito que procura opor valores semanticamente identificado pela dignidade humana. Ao nível fundamental da produção de sentido, o texto de Saramago baseia-se na relação contraditória entre opressão e libertação, sendo estes últimos colocados, em homologia com vida em oposição à morte, e natureza em oposição à cultura, identificado como uma forma de controle social.

Palavras-chave: Violência. José Saramago. Semiótica. Luta de classes. Mulher.

\begin{abstract}
This study focuses on the theme of violence in the literary work of José Saramago, Portuguese writer, so far the only one to win the Nobel Prize for Literature in Portuguese. Of all titles of this author, the following examples were separated for the present analysis, as they are representative of significant moments of his literary maturity: Levantado do Chão (1980), that one only for the introductory methodological exemplification, $O$ ano de 1993 (1975), Memorial do Convento (1982) and Ensaio sobre a cegueira (1995). The approach is based on analytical categories of Semiotics founded by Algirdas Julien Greimas, according to which any text has three levels of abstraction in the production of meaning: the fundamental level, the level of narrative and the discursive level. In the discursive level, it seems that Saramago's text reiterates themes and figures that confirm the ideological support of this writer to the interests of the oppressed classes in their historic mission of emancipation. In the process, women play a leading role in Saramago's text. On the narrative level, the discursive effect is accomplished by the representation of a subject that seeks to oppose values that are semantically identified with human dignity. In the fundamental level of production of meaning, Saramago's text is based on the contradictory relationship between oppression and liberation, the latter being placed in homology to life as opposed to death, and nature as opposed to culture, identified as a form of social control.
\end{abstract}

Keywords: Violence. José Saramago. Semiotics. Class struggle. Woman.

1 Professor Dr. do Departamento de Literatura e respectivo Programa de Pós-Graduação em Letras da Universidade Federal do Ceará (UFC). Doutor em Letras pela UFPB. E-mail: leiteufc@email.com 
O conjunto da obra do escritor português José Saramago revela um discurso com reiterada crítica à opressão de classes e suas diversas formas de violência. Em se tratando de trabalho de um expoente marxista, intelectual que fez da literatura sua militância, a violência aí representada obviamente não aparece como um ente genérico e descontextualizado, mas, muito pelo contrário, pressupõe uma concepção histórica, segundo a axiologia da luta de classes.

Dentre as diversas possibilidades de apreensão e análise do tema da violência na obra literária, faço a opção pela abordagem semiótica proposta por Greimas. Tenciono, pois, verificar como se constrói o sentido da violência no discurso literário. Para tanto, parto do pressuposto de que o sentido do texto (lido ou ouvido) não é bem aquilo que "magicamente" se manifesta ante os olhos ou ouvidos de quem lê ou escuta o relato, mas o que resulta da construção do sentido. Ato intersubjetivo por excelência, essa construção do sentido se realiza no compartilhamento social da língua mediante a enunciação, momento em que a língua se converte em fala (FIORIN, 1996, passim). A compreensão do texto funciona como um jogo contratual, cuja compreensão é proposta por um enunciador para o fazer interpretativo do enunciatário (GREIMAS; COURTÉS, 2008, p. 271).

A semiótica greimasiana constituiu um método próprio de apreensão do sentido, qualquer que seja a natureza do texto. Segundo a teoria de Greimas, a geração do sentido pode ser inferida em três níveis de abstração, como se fossem três camadas. O nível mais abstrato e profundo é chamado de fundamental, o nível intermediário é o narrativo e o mais adensado e externo deles é o discursivo. Se o sentido é gerado do nível mais abstrato para o menos abstrato, a análise da geração do sentido tende a fazer a reconstituição desse percurso no sentido inverso de sua produção, ou seja, do menos para o mais abstrato ou, em outras palavras, da aparência manifestada pelo texto para a imanência que lhe confere o próprio sentido.

A título de ilustração, proponho a leitura deste trecho, que introduz um dos capítulos de Levantado do chão:

Então chegou a república. Ganhavam os homens doze ou treze vinténs, e as mulheres menos de metade, como de costume. Comiam ambos o mesmo pão de bagaço, os mesmos farrapos de couve, os mesmos talos. (SARAMAGO, 1991b[1980], p. 923).

No nível menos abstrato, chamado nível discursivo, constrói-se uma rede semântica a partir de diversas isotopias, como são chamadas as reiterações semânticas produzidas ao 
longo do texto (GREIMAS; COURTÉS, 2008, p. 275). No trecho acima, percebe-se uma combinação de várias isotopias, como a política, lexicalizada por "república", a do gênero, lexicalizada por "homens" e "mulheres", a do trabalho, lexicalizada por "Ganhavam [...] doze ou treze vinténs", "menos da metade", a da subsistência, lexicalizada por "Comiam o mesmo pão de bagaço, os mesmo farrapos de couve [...]”, dentre outras (sistema monetário, cultura alimentar, historicidade, etc.). Também nesse nível, instala-se a chamada voz narrativa. Chamo atenção para o fato de que o texto não traz um "eu" que fala para um "tu" nas coordenadas do "aqui" e "agora", mas uma forma indireta de "contar" a história, na qual atuam "eles" (homens e mulheres), "lá" e "então" (a república foi proclamada em 1910), ou seja, índices que conferem ao texto um efeito de sentido de alteridade. Ora, tanto as isotopias temático-figurativas (valores e representações), que evocam um "efeito de realidade" como a forma dita objetiva do discurso em terceira pessoa (reforçado pela alteridade narrativa) contribuem para a objetividade típica dos textos de tendência realista (Realismo, Naturalismo, Neorrealismo, etc.), cujo efeito retórico convoca o enunciatário a aderir ao propósito ideológico do texto, que não esconde a preferência de classe pelos trabalhadores rurais, em nada beneficiados com a queda da monarquia em Portugal. Não custa ainda acrescentar, no âmbito da estratégia persuasiva, a ênfase para a superexploração da força de trabalho da mulher, no dizer do texto, vitimizada "como de costume". O foco na condição particular da mulher não aparece só nesse excerto, mas se generaliza no conjunto da obra de Saramago.

Num nível mais abstrato, chamado de narrativo, constrói-se um efeito de sentido de subjetividade. Entende-se por subjetividade, na metalinguagem semiótica, a relação transitiva entre um sujeito e um objeto-valor, que é proposto por um destinador na forma de pacto. No trecho destacado, há um claro conflito entre dois programas propostos como pacto ao sujeito investido na figura coletiva da classe trabalhadora rural. De um lado, um destinador não explicitado, que pode ser identificado como direito natural, lhe propõe o objeto-valor das condições materiais necessárias a uma vida digna; de outro, um destinador explicitado na figura da república, que pode ser associado ao direito positivado, propõe como pacto a conservação das relações de trabalho no campo (no contexto do romance, dominado pelo latifúndio), o que implica a disjunção da classe trabalhadora com as condições dignas de sobrevivência. Um conteúdo polêmico entre o querer e o dever se instala no sujeito virtualizado (pois a ação ainda está em estado de hipótese): de um lado o querer propõe a conjunção com as condições dignas de sobrevivência; de outro, o dever impõe a resignação imposta pelo "destino", ideologicamente justificado e reiterado pela tradição. A ação de

\begin{tabular}{|c|c|c|c|c|}
\hline Qonista Dialectus & Ano 2 & n.7 & Setembro - Dezembro 2015 & p. $94-103$ \\
\hline
\end{tabular}


ruptura com o pacto de manipulação do destinador (figurativizado pela república) só teria êxito com um saber (consciência de classe) e um poder (condições reais de reação), o que pressupõe um adjuvante, ou seja, aquele que traria o saber e o poder necessários a um sucesso de ordem revolucionária. Somente de posse desse saber é que a classe trabalhadora pode desmascarar a república, que parece ser libertadora, mas efetivamente não é. Ora, se não é, mas parece, a república é semanticamente identificada com a mentira (GREIMAS; COURTÉS, 2008, p. 532), o que carrega essa palavra de ironia histórica, pois etimologicamente república é justamente a coisa pública, ou seja, o poder político em posse do povo, e não de uma aristocracia ou de uma plutocracia.

Antes de passar para o nível mais abstrato da geração do sentido do trecho ainda em exame, chamo atenção para o fato de que a situação aí particularizada pode ser lida como metonímia de um esquema narrativo mais amplo, apresentado por Greimas (1976, p. 237) para ilustrar o modelo marxista de compreensão da história. Segundo esse esquema narrativo, certamente inspirado no Manifesto do Partido Comunista (MARX; ENGELS, 1990[1848], p. $35)^{2}$, o destinador é a história, que propõe como objeto-valor a sociedade sem classes ao destinatário, que é a humanidade. A constituição desse objeto instaura como sujeito o ser humano, que contará como adjuvante a classe trabalhadora, mas terá como oponente a classe burguesa.

No nível mais abstrato, chamado de nível fundamental - e concluindo a ilustração introdutória do modelo semiótico -, chega-se a um termo complexo constituído por dupla implicação negativa (dialética, portanto). No trecho escolhido, esse termo é representado pela dicotomia liberdade versus opressão. Negando-se a liberdade, chega-se à opressão; negandose a opressão, afirma-se a liberdade. No caso específico do trecho, esboçam-se dois movimentos: o da negação da liberdade e afirmação da opressão, que é proposto pelo continuísmo republicano (sob o disfarce revolucionário); e o da negação da opressão, que abre a hipótese do protagonismo histórico da classe trabalhadora rural lusitana (a reforma agrária e a revolução sem disfarces). Isso significa dizer que o sentido do texto como um todo, e não somente no trecho em foco, se constrói a partir dessa matriz semântica, cujo viés apresenta como positivo ou eufórico o sentido da negação da opressão. Mesmo a superexploração da mulher se constrói segundo essa tensão semântica, visto que o gênero não opõe homem a mulher, mas sobrepõe na mulher a condição da classe em que se ela se insere. Não é por acaso que o protagonismo de classe feminino é o mais enfatizado na obra de Saramago: duplamente

2 "La historio de la tuta ĝisnuna socio estas la historio de klasbataloj."

\begin{tabular}{|c|c|c|c|c|}
\hline Q & Anista \\
\hline
\end{tabular}


explorada na sua condição de classe, sua libertação será duplamente revolucionária. Concluindo esta introdução, vale ressaltar que, em homologia ao termo liberdade versus exploração, podem ser percebidas outras dicotomias, como os pares universais vida versus morte e natureza versus cultura, ou seja, no paradigma semântico da liberdade estão a vida (sobrevivência) e a natureza (insubordinação); do lado da opressão estão a morte (miséria e mazelas) e a cultura (estruturas de legitimação da classe dominante) (GREIMAS; COURTÉS, 2008, p. 520-522).

Passo agora a exemplos de legítima defesa e justiçamento, formas de resistência das classes oprimidas. Pelos motivos já expostos, destaco o protagonismo feminino nas representações de resistência à violência de classe. A bem da concisão, recolherei os exemplos de três livros, publicados em três momentos do amadurecimento literário do autor: $O$ ano de 1993 (1975), Memorial do Convento (1982) e Ensaio sobre a cegueira (1995). Nesses três livros (que não são os únicos exemplos), cabe ao ator feminino a eliminação do ator masculino metonimicamente identificado com a opressão da classe dominante.

O surrealista $O$ ano de 1993, escrito em versos prosaicos (sem metrificação), traz um cenário apocalíptico de sitiamento militar de uma população submetida aos mais extremos atos de barbárie, usando-se de um requinte tecnológico que lembra não só algumas obras de ficção científica como outras obras nada ficcionais, documentadas em sua crueza pela História. O paralelo com o nazismo é explicitado, como no trecho:

Quando os habitantes da cidade se tinham já habituado ao domínio do ocupante

Determinou o ordenador que todos fossem numerados na testa como no braço se fizera cinquenta anos antes de Auschwitz e outros lugares

A operação era indolor e por isso mesmo não houve qualquer resistência e sequer protestos

O próprio vocabulário sofrera transformações e haviam sido esquecidas as palavras que exprimiam a indignação e a cólera. (SARAMAGO, 1991a[1975], p. 168).

No entanto, esse domínio não dura para sempre, sendo derrotado por uma revolução, coroada pela eliminação dos opressores como forma de justiçamento:

E diziam os sofrimentos mútuos e riam chorando e mostravam as feridas dos combates e depois iam aos julgamentos dos invasores que todos seriam condenados à morte sem excepção

Porque eram os senhores da morte os empresários da tortura e por isso tinham de ser retribuídos na única moeda que conheciam. (SARAMAGO, 1991a[1975], p. 180). 
Antes, porém, é notório o protagonismo das mulheres, inclusive com o uso simbólico do próprio sexo como forma de resistência e vingança, visto que seus companheiros haviam sido violentamente assassinatos pelo exército invasor, além do fato de elas próprias serem tomadas como presas sexuais, forma bestial de sanção premial dada aos vencedores:

Será visto que estando mortos os homens perseguidos os perseguidores hãode violá-las conforme mandam as imemoriais regras da guerra

(...)

Cortam cerce os pênis do exército perseguidor que as vaginas cospem para fora com o mesmo desprezo com que os homens perseguidos haviam sido degolados

Uma só mulher porém enquanto as outras celebram a justa vitória retira suavemente o membro amputado que ainda tivera tempo de ejacular E levantada comprime o sexo com as mãos e afasta-se pela planície na direção das montanhas. (SARAMAGO, 1991a[1975], p. 154).

Se a quase totalidade das mulheres é dada a comemoração pela efêmera vitória, aliás sancionada como justa, como se constata pela voz do narrador, a uma em particular é dada a fecundação, que será levada em segredo para uma área de resistência: as montanhas. Simbolicamente, forma-se um termo complexo entre a opressão e a emancipação, visto que a violência do presente está fertilizando a resistência do futuro. Cabe aqui lembrar que o segredo é aquilo que não parece, mas é, ou seja, é a negação da manifestação, que é da ordem do parecer, para afirmação da imanência, que por sua vez é da ordem do ser, segundo o quadrado semiótico das modalidades veridictórias (GREIMAS; COURTÉS, 2008, p. 530533).

O romance Memorial do Convento simula o tempo do reinado de Dom João V, que durou de 1706 a 1750. Ao contrário das tradicionais ficções de fundo histórico, os protagonistas desse romance pertencem às classes populares, quais sejam, Blimunda e Baltasar, o casal que auxilia os projetos do padre Bartolomeu de Gusmão, chamado de Padre Voador por suas pesquisas precursoras da navegação espacial. Filha de Sebastiana de Jesus, condenada ao degredo pela inquisição, Blimunda é mulher com poderes sobrenaturais. Quando está em jejum, ela é capaz de ver as pessoas por dentro. Ela e o companheiro Baltasar, soldado que tivera a mão esquerda amputada em combate, tornam-se ajudantes do padre Bartolomeu de Gusmão na construção da passarola, uma fantástica máquina de voar movida pelas vontades humanas. Tendo sido Baltasar arrebatado num desastroso e involuntário voo da passarola, Blimunda vai procurá-lo no local ermo em que a máquina era escondida. Lá ela é assediada por um frade estuprador. Para defender-se, Blimunda vale-se do espigão que Baltasar usava no lugar da mão amputada, a um tempo instrumento de trabalho e

\begin{tabular}{|c|c|c|c|c|}
\hline Qonita Dialectus & Ano 2 & n.7 & Setembro - Dezembro 2015 & p. $94-103$ \\
\hline
\end{tabular}


eventual arma de defesa:

O vulto cobre toda a luz da fresta, é de homem alto e forte, ouve-se-lhe a respiração. Blimunda puxara o alforge para o lado, e, quando o homem se ajoelhou, meteu rapidamente a mão na bolsa, segurou o espigão pelo encaixe, como um punhal. Já sabemos o que vai acontecer, está escrito desde que em Évora o ferreiro fez o espigão e o gancho, um está aqui na mão de Blimunda, o outro quem o virá dizer. $\mathrm{O}$ frade tacteou os pés de Blimunda, afastou-lhe devagarinho as pernas, para um lado, para o outro, excita-o terrivelmente a imobilidade da mulher, porventura está acordada e lhe apetece o homem, já as saias foram atiradas para cima, já o hábito arregaçado, a mão avança a reconhecer o caminho, estremeceu a mulher, mas não faz outro movimento, jubiloso o frade empurra o membro para a invisível fenda, jubiloso sente que os braços da mulher se fecham nas suas costas, há grandes alegrias na vida de um dominicano.

Empurrado pelas duas mãos, o espigão enterra-se entre as costelas, aflora por um instante o coração, depois continua o seu trajecto, há vinte anos que este ferro procurava esta segunda morte. (SARAMAGO, 1991c[1982], p. 332).

No epílogo desse romance, Blimunda, tendo procurado o companheiro por nove anos, vai encontrá-lo prestes a morrer numa fogueira, coincidentemente no mesmo auto de fé em que, dentre outras vítimas, está sendo executado o dramaturgo brasileiro Antônio José da Silva, chamado o Judeu. Quando a passarola caiu, depois do voo involuntário, Baltasar acabou sendo capturado e entregue às autoridades eclesiásticas, que o acusaram do crime de bruxaria, condenando-o à morte.

No Ensaio sobre a cegueira, ocorre uma estranha epidemia de "cegueira branca". A região atingida tem as características urbanas contemporâneas, mas não é identificada, assim com as personagens, cujo nome é substituído pela função que exercem ou então por uma característica que as individualiza. Com o avanço da epidemia, os que iam ficando cegos eram mandados pelas autoridades sanitárias para um hospício. Em tal lugar é que se ensaia o essencial da tese sobre a relatividade da racionalidade humana. Algo do apocalíptico $O$ ano de 1993 permanece em exame nesse romance-ensaio, publicado vinte anos após aquele, que foi o último título da trilogia poética de Saramago.

No hospício, a única pessoa imune à cegueira era a, assim chamada, mulher do médico. Depois da tentativa fracassada de organização do lugar, por fim dominado por um grupo de cegos perversos, que, entre outras práticas abomináveis, usavam sexualmente as mulheres em troca dos alimentos por eles controlados, a mulher do médico decide matar como forma extrema de justiçamento:

A cama do chefe dos malvados continuava a ser a do fundo da camarata, onde se amontoavam as caixas de comida. Os catres ao lado do seu tinham

\begin{tabular}{|c|c|c|c|c|}
\hline Q Rovista Dialectus & Ano 2 & n.7 & Setembro - Dezembro 2015 & p. $94-103$ \\
\hline
\end{tabular}


sido retirados, o homem gostava de mexer-se à vontade, não ter de tropeçar nos vizinhos. Ia ser simples matá-lo. Enquanto lentamente avançava pela estreita coxia, a mulher do médico observava os movimentos daquele que não tardaria a matar, como o gozo o fazia inclinar a cabeça para trás, como já parecia estar a oferecer-lhe o pescoço. Devagar, a mulher do médico aproximou-se, rodeou a cama e foi colocar-se por trás dele. A cega continuava no seu trabalho. A mão levantou lentamente a tesoura, as lâminas um pouco separadas para penetrarem como dois punhais. Nesse momento, o último, o cego pareceu dar por uma presença, mas o orgasmo retirara-o do mundo das sensações comuns, privara-o de reflexos, Não chegarás a gozar, pensou a mulher do médico, e fez descer violentamente o braço. A tesoura enterrou-se com toda a força na garganta do cego, girando sobre si mesma lutou contra as cartilagens e os tecidos membranosos, depois furiosamente continuou até ser detida pelas vértebras cervicais. (SARAMAGO, 1995, p. 185).

Nas três situações selecionadas, a representação do ato de defesa da mulher tem seu sentido construído numa isotopia temático-figurativa que confirma e reitera um padrão de valores caros a um autor marxista como Saramago. Em todos os casos, a isotopia da violência sexual flagra uma relação assimétrica entre o masculino e o feminino, cujo saldo é a reificação da mulher. Do ponto de vista semiótico, tal reificação representa uma relação de disjunção de um sujeito com o objeto-valor aí figurativizado pelo traço semântico humano: a conjunção sexual violenta significa a negação simbólica da humanidade à mulher, que passaria a ser considerada como coisa.

Numa leitura apressada, o discurso pode dar a impressão de opor entre si os gêneros masculino e feminino, tomados em sentido absoluto, e não situado num contexto histórico específico. No entanto, em todos os casos a resistência protagonizada pela mulher é solidária com o masculino coadjuvante de classe, segundo a axiologia da luta de classes. Para afastar essa falsa hipótese de guerra entre os sexos, passo em revista os três episódios examinados:

No primeiro excerto, a violência revolucionária das mulheres vinga o assassinato dos companheiros pelo exército invasor. Há, pois, o gesto solidário para com os companheiros de classe.

No segundo, Blimunda usa o instrumento de defesa do próprio companheiro para matar o frade estuprador, sendo ela fiel a Baltasar de corpo e arma (o espigão). O uso do espigão tem uma força simbólica notável: esse instrumento substitui a canha, a mão que colhe enquanto a destra ceifa, podendo tanto colher o alimento, quando tomado como instrumento de trabalho, como a vida do inimigo, se tomado como instrumento de defesa. A tempo, é a propósito da mão esquerda de Baltasar que o padre Bartolomeu de Gusmão elabora uma curiosa heresia. Segundo o padre cientista, não há em todo o Novo ou Velho Testamento uma 
só menção à mão esquerda de Deus. Disso ele deduz que o Criador do Universo só teria a mão direita - e por que necessitaria de ambas as mãos? Baltasar fica assustado com a imagem de uma divindade maneta, por certo sem perceber que a divindade estava metaforizada nele mesmo, na sua dimensão humana representada como imagem e semelhança de Deus.

No terceiro, a mulher do médico age solidariamente com os cegos oprimidos ao matar o chefe do bando que mantinha o estado de opressão e barbárie no âmbito do hospício, tendo agido quando este violentava uma mulher, que se via na condição de trocar seu corpo pela comida criminosamente retida. $\mathrm{O}$ fato de ser a única a enxergar confere-lhe um saber e um poder necessários ao desempenho que culmina com a vitória dos oprimidos sobre os opressores. Considerando-se o estado de ensaio dessa ficção, entende-se que o saber e o poder são os modalizadores imprescindíveis para o alcance do objeto-valor investido semanticamente como emancipação. É notório, nesse livro, o valor simbólico do olhar, que recupera a metáfora da luz e do esclarecimento iluministas, visto que constituíram promessas históricas ainda por alcançar. A mesma metáfora prossegue no romance Ensaio sobre a lucidez (2004), que novamente trará o protagonismo feminino à frente de uma revolução provocada pela anulação do voto e o desmascaramento de uma democracia de aparências.

Nos três casos, a defesa do próprio corpo é também a defesa do corpo social ao qual se vincula a mulher. Há, portanto, uma homologia entre a resistência feminina e a reação das classes oprimidas, sabendo-se que é justamente a mulher aquela que sofre uma dupla reificação: a de classe social, coisificada para o trabalho, nas relações de produção impostas pela sociedade estratificada, e a de gênero, coisificada para o consumo como objeto sexual. Para dupla violência, enfim, o texto de Saramago ministra uma redobrada resistência. Nesses casos, vale ainda lembrar, a subtração da vida é cogitada, pois a eliminação do inimigo ganha o investimento semântico da legítima defesa.

Em síntese, o discurso de Saramago reitera temas e figuras que confirmam sua adesão ideológica às classes oprimidas, em sua missão histórica de emancipação, sabendo-se que a mulher tem lugar de protagonista nesse processo revolucionário. No plano narrativo, esse propósito discursivo se efetiva pela representação de um sujeito que busca como objeto-valor identificado semanticamente pela dignidade humana. No nível fundamental da produção do sentido, o texto de Saramago fundamenta-se na relação contraditória entre opressão e emancipação, sendo esta última colocada em homologia à vida, em oposição à morte, e à natureza, em oposição à cultura, identificada esta como forma de controle social. 


\section{REFERÊNCIAS}

FIORIN, José Luiz. As astúcias da enunciação: as categorias de pessoa, espaço e tempo. São Paulo: Ática, 1996.

GREIMAS, Algirdas Julien; COURTÉS, Joseph. Dicionário de semiótica. Trad. Alceu Dias Lima et al. São Paulo: Contexto, 2008.

GREIMAS, Algirdas Julien. Semântica estrutural. Trad. Haquira Osakabe e Izidoro Blikstein. 2.ed. São Paulo: Cultrix, 1976.

MARX, Karl; ENGELS, Friedrich. Manifesto de la komunista partio. Trad. Detlev Blanke [alemão-esperanto]. Moscou: Progreso, 1990.

SARAMAGO, José. Ensaio sobre a cegueira. São Paulo: Companhia das Letras, 1995.

SARAMAGO, José. Levantado do chão. In: . Obras de José Saramago. Porto: Lello e Irmão, 1991. v.2.

SARAMAGO, José. Memorial do convento. In: Obras de José Saramago. Porto: Lello e Irmão, 1991. v.3 .

SARAMAGO, José. O ano de 1993. In: Irmão, 1991. v.1. Obras de José Saramago. Porto: Lello e 